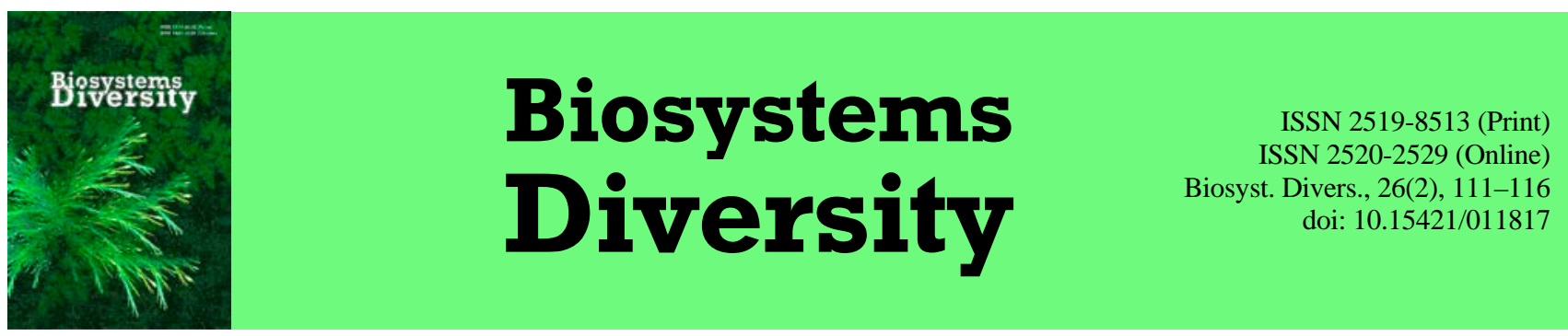

\title{
Motor activity of Daphnia magna (Crustacea, Cladocera) during thermal selection: Peculiarities of search reactions in the non-uniform environment
}

\author{
V. B. Verbitsky*, N. Y. Poddubnaya**, T. I. Verbitskaya* \\ *Papanin Institute for Biology of Inland Waters RAS, Borok, Russia \\ **Cherepovets State University, Cherepovets, Russia
}

Article info

Received 19.04.2018

Received in revised form 09.05 .2018

Accepted 10.05.2018

Papanin Institute for Biology of Inland Waters RAS,

Borok, 153742, Russia.

Tel.: +7-960-537-57-42

E-mail: werb@ibiw.yaroslavl.ru

Cherepovets State University, Lunacharskogo av., 5 ,

Cherepovets, 162600, Russia.

E-mail: poddoubnaia@mail.ru

\begin{abstract}
Verbitsky, V. B., Poddubnaya, N. Y., \& Verbitskaya, T. I. (2018). Motor activity of Daphnia magna (Crustacea, Cladocera) during thermal selection: Peculiarities of search reactions in the non-uniform environment. Biosystems Diversity, 26(2), 111-116. doi:10.15421/011817
\end{abstract}

We conducted a study of the peculiarities of the motor activity of juvenile and adult individuals of Daphnia magna in the process of thermal selection. On the example of Daphnia, we experimentally proved the assumption that the decrease in the motor activity of the ectotherms in the selected temperature range is a behaviour mechanism typical for thermal selection. The experiment was conducted on the offspring of one parthenogenetic female (pure line) of a laboratory culture maintained over several years at room temperature. The Daphnia individuals had been beforehand acclimated over several generations to $23.4{ }^{\circ} \mathrm{C}$, and then were placed in a thermogradient apparatus. The control individuals were maintained at room temperature. The final temperature preference was determined using the so-called "chronic" method, when the tested organisms are maintained in a thermogradient apparatus over several days. The positions of the Daphnia individuals were recorded daily during 24 days. As a parameter which would characterize the motor activity of Daphnia, we used the parameter of average relative shifting, which was calculated as a difference (in $\mathrm{cm}$ ) between the position they were found in two sequential records, divided by time (in min) between these records. Over the first 3 days, in the conditions of the temperature gradient, the Daphnia mostly selected heightened temperatures $\left(24-28{ }^{\circ} \mathrm{C}\right)$. During the period from the 4th to 24th day, 74\% of the Daphnia selected the range of 18 $23{ }^{\circ} \mathrm{C}$ and $85 \%-17-24{ }^{\circ} \mathrm{C}$. Thus, the range of the ultimate selected temperatures decreased by $4{ }^{\circ} \mathrm{C}$ compared to the initially selected temperatures and enlarged by $3{ }^{\circ} \mathrm{C}$ towards the lower temperatures. In the thermogradient apparatus, the parthenogenetic females had the lowest value of the mean relative movement. In the control, at room temperature, this parameter of the adults was by $43 \%$ higher compared to the gradient. The pattern of the dynamic of the indicator in both variants of the experiment was similar for the periods and phases of fluctuations. With the juveniles the value of the parameter of mean relative shifting in the gradient was higher by $40 \%$ compared to the adult Daphnia, but close to the parameter of the adults in the control. We determined a relationship between the juveniles selecting the higher temperatures and higher mean relative shifting, which indicates a relationship between the behavioural selective reaction of juvenile Daphnia and general physiological condition of their organism. During the absence of the temperature gradient, the Daphnia were observed to show symmetry in their motor reaction. Occurrence of the asymmetry of the motor reaction of the Daphnia in the condition of the thermogradient, manifesting in the prevalence of shifting to lower or higher temperatures, can indicate more clearly manifested search reaction in the condition of a non-uniform environment.

Keywords: behaviour reactions; ultimate temperature preferendum; temperature gradient; acclimation

\section{Introduction}

The ability for search behaviour in the conditions of a thermally heterogeneous environment occurs due to the peculiarities of the physiology of ectotherms, which allow them to sense insignificant temperature differences. Therefore, for example, it was determined that fish can feel a difference in the temperature, that equals $0.03{ }^{\circ} \mathrm{C}$ (Bardach \& Bjorklung, 1957; Steffel et al., 1976). For large crustaceans, the parameters are determined to be $1.0^{\circ} \mathrm{C}$ for the American lobster (Homarus americanus) (Jury, 2000), to $1.3-2.0^{\circ} \mathrm{C}$ for the European crayfish (Astacus astacus) (Kivivuori, 1994) and 2.1-4.2 ${ }^{\circ} \mathrm{C}$ for Procambarus clarkii (Espína, 1993). For Daphnia, according to the results of the experiments in thermogradient devices, it was determined that they react to average changes in the temperature which equal 0.2 $0.5^{\circ} \mathrm{C}$ (Gerritsen, 1982).

No thermoreceptors or thermoregulating centres have been identified in crustaceans. Therefore, it is considered that their thermal behaviour is based on non-directed behaviour mechanisms (orthoki- neses and klinokineses) which are caused by changes and differences in the temperatures (Lagerspetz \& Vainio, 2006). However, there are no articles known to us, apart from the abovementioned, which include research on the behavioural mechanisms of the formation of the final temperature selection of Cladocera and, particularly, the peculiarities of their behaviour in the conditions of a temperature gradient.

The other completely unstudied aspect is whether the lower crustaceans (Branchiopoda) have symmetry or asymmetry in their behavioural selective reactions. The lower vertebrates (Anamnia) exhibit bilateral asymmetry in their reactions, but this is usually considered to be related to the functional asymmetry of the CNS: the animals usually focus on an object with a certain eye - left or right (Andrew, 2009). Using various experimental methods, such asymmetry has been found for birds, reptiles and amphibians (Vallortigara \& Bisazza, 2002). It is now being actively studied for teleosts (Andrew et al., 2009; Miklosi et al., 1997, 2001; Miklosi \& Andrew, 1999; Nepomnyashchikh \& Izvekov, 2007; Takeuchi et al., 2010; Izvekov \& Nepomnyashchikh, 2013). Therefore, the example of the larvae of zebra fish demonstrates the 
forming of series of rotations directed to one side, and the sequence of these series occurs spontaneously under the impact of the central oscillator, and not as a response to external stimulation (Romanovski et al., 2014). A similar sequence of series of rotations to the right and left was found in barred flagtail Kuhlia mugil Forster (Kuhliidae). (Gautrais et al., 2009). Also, it was determined that in a uniform environment, the spontaneous organizing of behaviour manifests as the so-called interrupted search which consists of two interchanging phases - moving and exploring (Nepomnyashchikh, 2000). Such reactions have never been studied for the lower crustaceans. All that is known is that Lagerspetz and Vainio (Lagerspetz \& Vainio, 2006) assumed that the decrease in the activity of the Daphnia is a general behavioural mechanism which occurs during thermal selection.

The objective of the paper is the study of the peculiarities of the motor activity of juvenile and adult Daphnia magna Straus which were maintained in a thermogradient device over a long period compared to individuals which were maintained in water at room temperature.

\section{Material and methods}

The final selected temperature (FTS) was determined using the so-called "chronic" method (Reynolds \& Casterlin, 1979; Rosetti et al., 1989; Verbitsky \& Verbitskaya, 2012; Golovanov, 2013), when the tested organisms are kept in a thermogradient device for several days. For the analysis, we used the data obtained in the course of identifying the final selected temperature (FTS) among the offspring of one parthenogenetic female Cladoceran D. magna (pure line) of laboratory culture which were kept over several years at room temperature. The Daphnia were beforehand acclimated to the constant temperature of $23.4^{\circ} \mathrm{C}$ over several generations.

The device for studying the selected temperature was a Herter's tray with a metal bottom and walls of transparent acrylic glass (Fig. 1). The size of the trays was $180 \times 1.5 \times 2.5 \mathrm{~cm}$. The horizontal gradient $\left(\sim 0.1^{\circ} \mathrm{C} / \mathrm{cm}\right)$ was made by maintaining different temperatures on the opposite sides of the tray $\left(4-8\right.$ to $\left.28-30^{\circ} \mathrm{C}\right)$ with a UTP- 1 thermoregulating device, a heating element of $0.8 \mathrm{~kW}$ power and a cooling aggregate. For preventing the convectional flow and vertical gradient, the water thickness in the tray was $10-12 \mathrm{~mm}$. This allowed creation of a sufficiently gradual horizontal temperature, gradient which equaled about $0.1^{\circ} \mathrm{C} / \mathrm{cm}$. For recording the water temperature along the tray at fixed points, we installed thermometers at $10 \mathrm{~cm}$ intervals. The temperature measurement was accurate to $0.1^{\circ} \mathrm{C}$. The values of the temperature were recorded every hour. The difference between the two sequential records could equal $\sim 0.0-0.7^{\circ} \mathrm{C}$. After the experiment, using these data, the crustaceans' positions were converted from linear to temperature values. The tray was divided by lateral non-transparent barriers into three sections, each containing 1 adult parthenogenetic $D$. magna female. The Daphnia were put into the sections at the temperature of acclimation.

Three control Daphnia from the same clone as the experimental individuals, also provisionally acclimated to $23.4^{\circ} \mathrm{C}$, were put into the control tray divided into three sections and filled with water at room temperature. On different days, the water temperature equaled 18$22{ }^{\circ} \mathrm{C}$. At the end of each day, after the end of taking observations, a suspension of chlorella (Chlorella sp.) was added in equal portions the full length of each tray to the amount of $5.0-7.5 \cdot 10^{5} \mathrm{cell} / \mathrm{ml}$ and filtrated river water diluted with a distillate in the proportion of $1 / 2$ was added for achieving a constant level. Before the addition of fresh food, the sediment on the bottom of the trays was removed using a pipette.

The tray of the apparatus was uniformly illuminated by 8 lamps (40 W each) of the daylight. Two were placed along the tray at $46 \mathrm{~cm}$ height and 6 - on the ceiling at $1.4 \mathrm{~m}$ distance from the tray. The illuminance above the water surface was $\sim 700$ lux. The experiments were conducted at the photocycle of $9 / 15 \mathrm{~h}$ (light/dark).

The indications of Daphnia positions were recorded daily in a periodicity of 20-30 min from 8:30 to $16: 40$ during 24 days. The young born by the females over the experiment were left in the trays for 3-5 days and then removed. In total, during the experiment, we recorded 702 observations of the adult Daphnia from the control and experimental trays and 1,826 observations of the young individuals from the experimental trays.

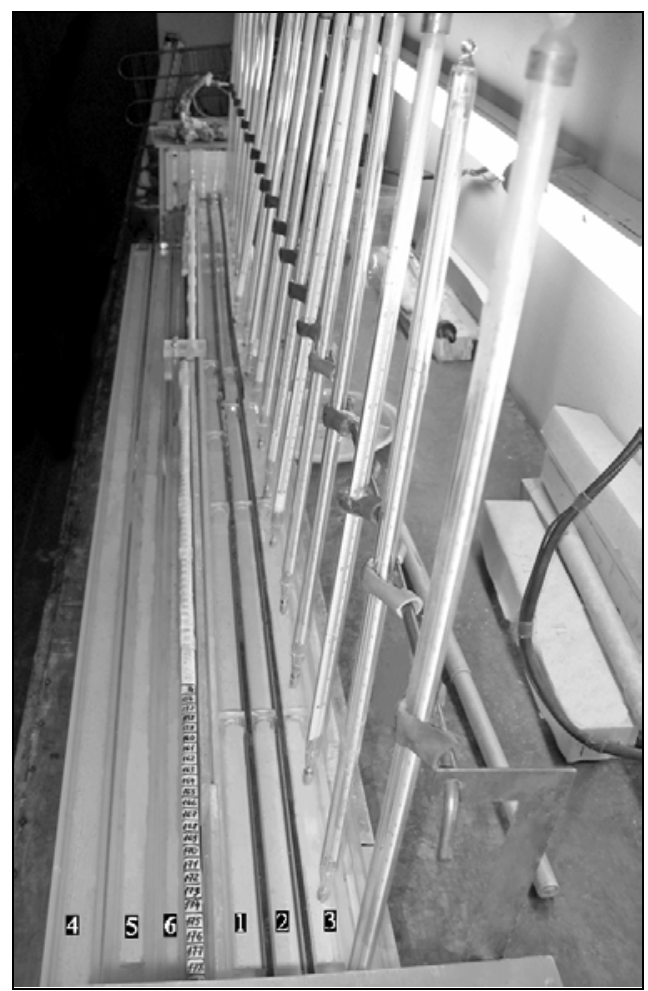

Fig. 1. Thermogradient apparatus: 1, 2, 3-the sections of the gradient apparatus; 4, 5, 6- the sections of the control tray

As a parameter which characterizes the motor activity of Daphnia, we used the parameter of mean relative shifting ( $\Delta$ Saver), which was calculated as the difference (in $\mathrm{cm}$ ) in the position of an individual during two sequential observations divided by the time (in min) between these records. The presence and reliability of the relation between the different parameters were evaluated using the coefficients of Spearman rank correlation. The statistical analysis of the data was conducted in the R statistical pack, version 3.2.2 (R Development Core Team, 2015).

\section{Results}

Three adult Daphnia females had similar dynamics of selected temperatures. The calculation of the coefficients of Spearman rank correlation indicated the absence of statistically reliable differences between the sequences of data $\left(\mathrm{R}_{21-2}=0.74\right.$ at $\mathrm{P}<0.001 ; \mathrm{R}_{21-3}=0.48$ at $\mathrm{P}=0.023 ; \mathrm{R}_{22-3}=0.67$ at $\mathrm{P}<0.001$ ). This allowed the data on these three individuals to be united into one sum and further to be analysed as three replications of one experiment.

After the Daphnia were put in conditions of temperature gradient, over the first 3 days, they mostly chose high temperatures of 24.0$27.9^{\circ} \mathrm{C}(88.5 \%$ of records). Starting from the 4 th day, the temperature selection (TS) shifted to the area of lower temperatures. From the 4th to 15th day, the level of TS manifestation reduced, and the range enlarged, the values of TS fluctuated from 19 to $25^{\circ} \mathrm{C}(86.2 \%$ of the records). From the 16th day and to the end of the monitoring, the values of TS fluctuated from 16 to $22{ }^{\circ} \mathrm{C}$ ( $89 \%$ of records). On the whole, over the period from the 4th to 24th day, $74 \%$ of the Daphnia selected the range of $18-23{ }^{\circ} \mathrm{C}$ and $85 \%$ - the range between 17 $24{ }^{\circ} \mathrm{C}$. Thus, the range of the final selected temperatures decreased by $4 \%$ compared to the initially selected temperatures and enlarged by 3\% towards lower temperatures (Fig. 2).

After comparing the curves of distribution of mature Daphnia in the control and experimental trays over the period from the 5th to 
24th day, developed using the average data for every $10 \mathrm{~cm}$, we can see that at room temperature, the Daphnia were distributed relatively uniformly along the tray (at each point $-3.9-6.7 \%$ of the records) (Fig. $3 a$ ). In the gradient of temperatures, we observed clearly manifested selection in the range of $40-110 \mathrm{~cm}$, where $69.1 \%$ of the records were concentrated (at each point $-5.5-12.9 \%$ of the records) (Fig. 3b). Outside the zone of selection, the number of the records at each point fluctuated from $0.2 \%$ to $4.9 \%$.

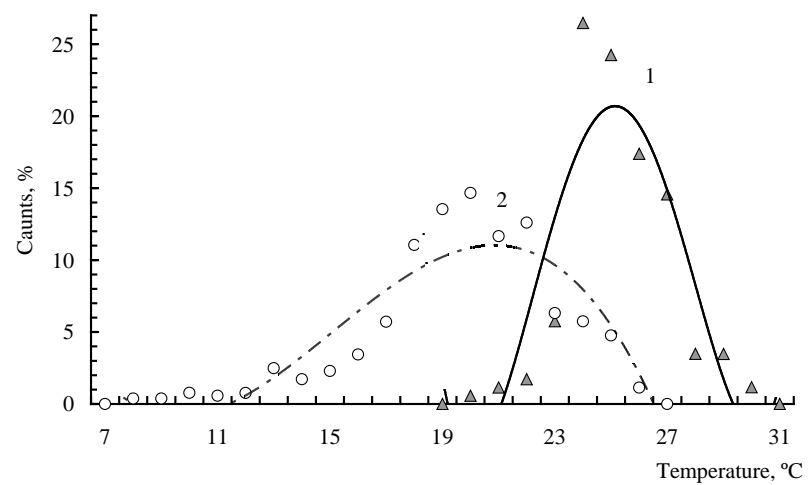

Fig. 2. Distribution of mature D. magna females in the thermogradient: 1 - over 1-4th days of the experiment, 2 - over the 5-24th days of the experiment
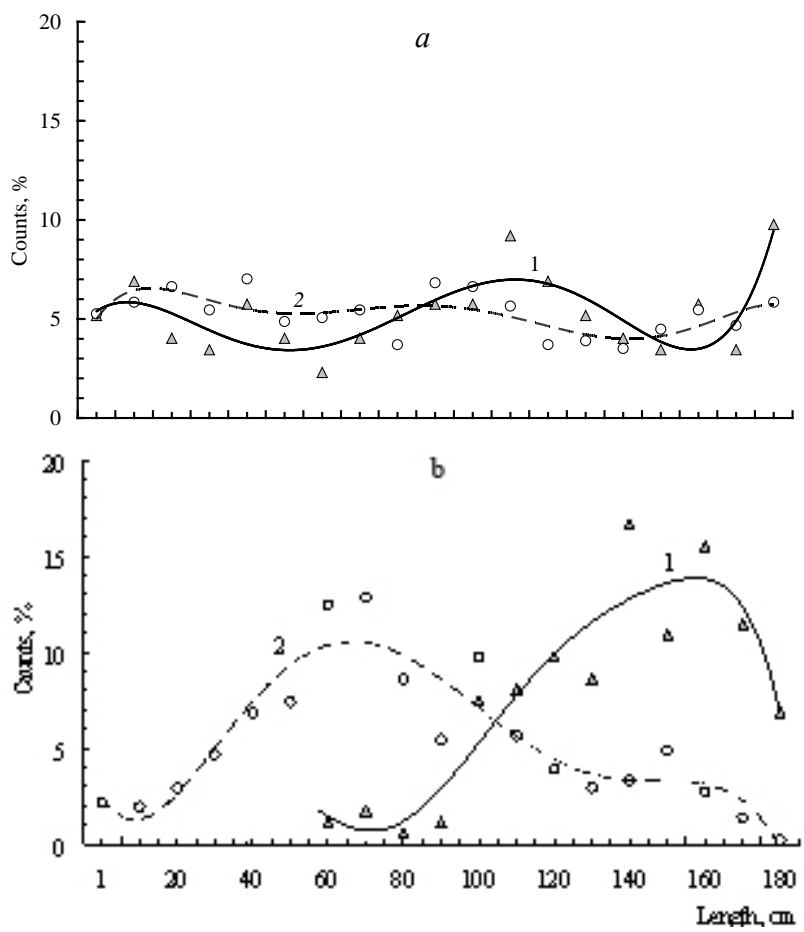

Fig. 3. Distribution of the Daphnia in the control tray (a) and in the tray with temperature gradient (b): 1 - days 1-4, 2 - days 5-24

The young individuals chose the highest temperatures. At the same time, the curve of distribution of the young was more extended along the scale of temperatures and had two maximum values - at $24-25{ }^{\circ} \mathrm{C}\left(27 \%\right.$ of the records) and at $28^{\circ} \mathrm{C}$ ( $7 \%$ of records). The temperature preferences of the young ranged from $19-28{ }^{\circ} \mathrm{C}$ in $85 \%$ of all records. The analysis of the dynamics of relative shifting of the Daphnia over the experiment indicated that the adult individuals in the condition of the temperature gradient demonstrated minimum activity. Their mean relative shifting equaled $0.6 \pm 0.2 \mathrm{~cm} / \mathrm{min}$ (Fig. 4). At the same time, the difference between the periods of relatively large (on the 1-2nd and 21-22nd day) and relatively small (8-20th day) shifting equaled 33.8-43.3\% (Table).

In the control trays, the mature Daphnia individuals were much more active than in the temperature gradient. The value of their mean relative shifting $(1.1 \pm 0.2 \mathrm{~cm} / \mathrm{min})$ was $43.4 \%$ higher than in the gradient. However, Figure 1 shows that the pattern of dynamics in the control and experimental trays was similar in the period and phases of fluctuations. The amplitude of the fluctuations, measured in absolute values, was higher in the control than in the gradient. However, the differences between the mean minimum and maximum values of shifting in relative values equaled $35.6-37.4 \%$, i. e. this parameter ranged within the same values as in the experimental variant (Table). The coefficient of Spearman rank correlation between the two variants $(0.68$ at $\mathrm{P}=0.007)$ also supports the statistical significance of the similarity in the pattern of dynamics.

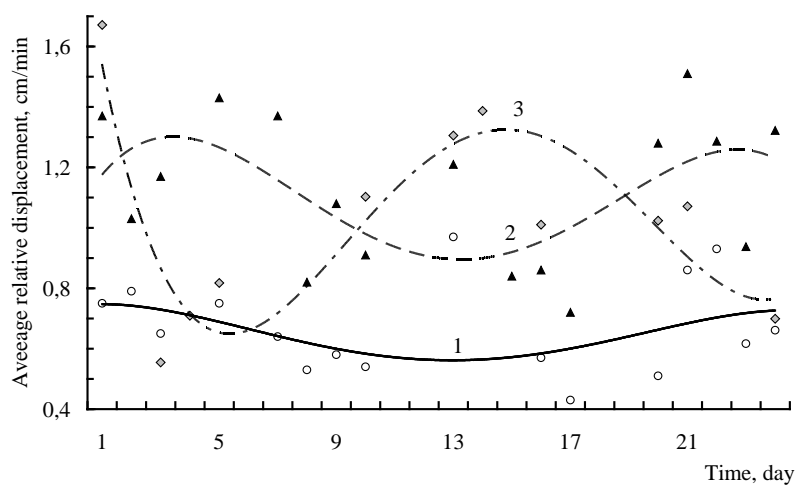

Fig. 4. The dynamic of relative shifting $\left(\Delta \mathrm{S}_{\text {aver }}\right)$ of one $D$. magna individual per unit of time: 1 - parthenogenetic females in the gradient, 2 - parthenogenetic females in the control, 3 - juvenile individuals in the gradient

\section{Table}

Dynamic of the mean relative shifting $\left(\Delta \mathrm{S}_{\mathrm{aver}}\right)$ of the Daphnia over the experiment

\begin{tabular}{|c|c|c|c|c|}
\hline & \multicolumn{4}{|c|}{ Periods of the observation * } \\
\hline & 1 & 2 & 3 & 4 \\
\hline \multicolumn{5}{|c|}{ Parthenogenetic females in the gradient } \\
\hline Time, day & $1-2$ & $8-20$ & $21-22$ & - \\
\hline$\Delta \mathrm{S}_{\text {aver }} \pm$ standard deviation, $\mathrm{cm} / \mathrm{min}$ & \multicolumn{3}{|c|}{$0.77 \pm 0.03 \quad 0.51 \pm 0.07 \quad 0.90 \pm 0.05$} & - \\
\hline Difference between the periods, \% & & 33.8 & 43.3 & \\
\hline \multicolumn{5}{|c|}{ Parthenogenetic females in the control } \\
\hline Time, day & $1-7$ & $8-17$ & $20-24$ & - \\
\hline$\Delta \mathrm{S}_{\mathrm{aver}} \pm$ standard deviation & $1.39 \pm 0.0$ & $30.87 \pm 0.12$ & $1.35 \pm 0.11$ & - \\
\hline e between the periods, \% & & 37.4 & 35.6 & \\
\hline \multicolumn{5}{|c|}{ Juvenile individuals in the gradient } \\
\hline Time, day & 1 & $3-5$ & $13-14$ & 24 \\
\hline$\Delta \mathrm{S}_{\mathrm{aver}} \pm$ standard deviation, $\mathrm{cm} / \mathrm{min}$ & 1.67 & $0.69 \pm 0.13$ & $1.35 \pm 0.06$ & 0.70 \\
\hline Difference between the periods, $\%$ & & 142 & 95.7 & 92.9 \\
\hline
\end{tabular}

Note: 1 and 3 - periods of high values of $\Delta \mathrm{S}_{\text {aver, }}, 2$ and 4 - periods of low values of $\Delta_{\text {Saver. }}$

The juveniles in the conditions of the temperature gradient were much more active than the adult Daphnia. The pattern of the dynamic of relative shifting of the young individuals was also fluctuating, with the same period as the mature individuals, but with significantly higher amplitude. The difference of the $\Delta \mathrm{S}_{\text {aver }}$ value between the periods of large and small shifts equaled $1.1 \pm 0.3 \mathrm{~cm} / \mathrm{min}$, i. e. approximately the same as among the adults in the control and by $40.2 \%$ higher than the adults in the gradient.

The comparative analysis of minimum $\left(\Delta \mathrm{S}_{\min }\right)$ and maximum $\left(\Delta \mathrm{S}_{\max }\right)$ values of relative shifting of the Daphnia (Fig. 5) indicates that the $\Delta \mathrm{S}_{\min }$ values in the conditions of temperature gradient were close in the young and adult individuals $(0.3-0.4 \mathrm{~cm} / \mathrm{min})$. In the control, the border minimum activity was 2.1 times higher $(0.7 \mathrm{~cm} / \mathrm{min})$. The $\Delta \mathrm{S}_{\max }$ values of the mature individuals in the gradient $(1.0 \mathrm{~cm} / \mathrm{min})$ were 2.6 times higher than $\Delta \mathrm{S}_{\min }$, and 2.1 times higher in the control. The juvenile individuals demonstrated the highest values of $\Delta \mathrm{S}_{\max }$ $(1.7 \mathrm{~cm} / \mathrm{min})$, which exceeded $\Delta \mathrm{S}_{\min }$ by 5.6 times.

During the transitional period (1-4 days), the young and mature Daphnia were observed to have a similar motor activity (Fig. 6a). In the zone of optimum temperatures, the $\Delta \mathrm{S}_{\mathrm{aver}}$ values both of the juvenile and adult Daphnia remained at one minimum level $(0.7 \mathrm{~cm} / \mathrm{min})$. But the range of $\Delta \mathrm{S}_{\mathrm{aver}}$ values independent from the temperature (plateau 
zone which corresponds to the optimum zone) was twice as large $\left(18.5-28.5^{\circ} \mathrm{C}\right)$ compared to the adults $\left(22.5-27.0^{\circ} \mathrm{C}\right)$. It enlarged towards low temperatures by $4.0^{\circ} \mathrm{C}$, and by $1.5^{\circ} \mathrm{C}$ towards high. The juveniles also had a larger range of $\Delta \mathrm{S}_{\text {aver }}$ values compared to adult females. The mean values of standard deviations of the juvenile Daphnia equaled 0.9 , and 0.7 of the adults. Higher activity of the young was manifested also in the fact that they were found at significantly lower temperatures than the adults ( 12.5 and $21.0{ }^{\circ} \mathrm{C}$ respectively), demonstrating maximum values of $\Delta \mathrm{S}_{\mathrm{aver}}$ at these temperatures (4.1$4.7 \mathrm{~cm} / \mathrm{min})$. After the transitional process and as the FST level was reached, the range of independence of the $\Delta$ Saver level from the selected temperature (ST) significantly enlarged in both age groups of Daphnia (Fig. 6b). Thus, with the young the upper border zone of the plateau remained at the same level as in the transitional period $\left(28.5^{\circ} \mathrm{C}\right.$ and the lower border shifted from 18.5 to $13.5^{\circ} \mathrm{C}$ ). As a result the plateau zone extended by $1 / 3$. For the adult Daphnia, the upper border of the plateau zone declined from 27 to $25^{\circ} \mathrm{C}$, and the lower - from 22.5 to $8,5^{\circ} \mathrm{C}$, i. e. the plateau zone enlarged almost 4 times. The motor activity of the adult Daphnia decreased compared to the transitional period (from 0.7 to $0.6 \mathrm{~cm} / \mathrm{min}$ ), and that of the young increased from 0.7 to $1.0 \mathrm{~cm} / \mathrm{min}$. The range of the $\Delta \mathrm{S}_{\text {aver }}$ values, determined using the value of standard deviation, increased from 0.9 to 1.2 among the young, and remained at the level of 0.7 among the adult females.

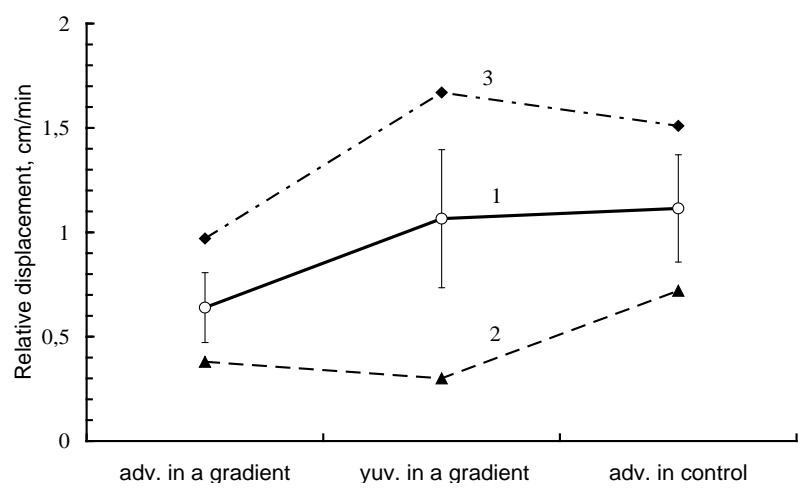

Fig. 5. Mean minimum and maximum relative shift of the $D$. magna individuals in the experiment: $1-\Delta \mathrm{S}_{\mathrm{aver}}, 2-\Delta \mathrm{S}_{\min }, 3-\Delta \mathrm{Smax}$; vertical lines - standard deviations of $\Delta \mathrm{S}_{\mathrm{aver}}$

For checking the symmetry of behavioural selective reactions of the Daphnia in the control and in the experiment, we analyzed the dynamic of percentage ratio of the number of shifts, when the Daphnia moved towards the higher temperatures and towards the decreasing temperatures (in the control, this movement corresponded to the right and to the left along the chamber respectively). In the control, the dynamic of the number of shifts of adult females to the right or to the left had a symmetrical fluctuating pattern with a constant period of 7.5 days with an amplitude which increased from period to period (510\%) (Fig. 7a). The calculation of the coefficients of Spearman rank correlation indicated the absence of reliable differences between the sequences of data in the replications $\left(\mathrm{R}^{2}=0.81\right.$ at $\left.\mathrm{P}<0.001\right)$. In the gradient, the adult females maintained a fluctuating regime for the first 10 days, but beginning from day 13, the symmetry was disrupted and by day 23 , the shifting towards the decreased temperature reliably dominated by $2-18 \%\left(\mathrm{R}^{2}=0.40\right.$ at $\left.\mathrm{P}=0.20\right)$ (Fig. $\left.7 b\right)$. At the same time, the amplitude of fluctuations during the first 10 days was close to the values in the control ( 7\%), and after day 13 , it increased to $16 \%$. Initially the young Daphnia in the thermogradient had no cyclicity in the number of shifts (Fig. 7c). Beginning from day 15, the shifts towards the increased temperatures predominated by $7-10 \%$, and from day 17 to 24 - towards the decreased temperature. However, this difference was not statistically reliable $\left(\mathrm{R}^{2}=0.69\right.$ at $\left.\mathrm{P}=0.003\right)$.

\section{Discussion}

As we know, the level of motor activity of ectotherms is one of the most significant components of their food procuring efficiency and their capacities of adapting to habitat in general (Wang \& Greenfield, 1994; Gorska-Andrzejak \& Wojtusiak, 2003).

The lower activity determined for adult individuals of $D$. magna in the gradient compared to the control could have been caused by one of two factors. The first cause - in the conditions of temperature gradient, the Daphnia were "seized" in the central favourable zone by the non-favourable temperatures from the edges of the trays, while those in the control trays could travel along all the entire length of trays. The second cause could be the abovementioned (Lagerspetz \& Vainio, 2006) assumption that the decrease in the motor activity is a general behavioural mechanism which occurs during thermal selection.

The first cause is supported by the fact that the Daphnia in the control were distributed relatively uniformly all along the trays (Fig. 6a), whereas in the conditions of the temperature gradient, the distribution showed a clear pattern of preference (Fig. 6b). However, the presence of a fully avoided zone was observed only over the first four days of the experiment in the transitional period, when the crustaceans selected higher temperatures and totally avoided $1 / 3$ of the length of the trays $(0-60 \mathrm{~cm})$ with low temperatures. Throughout the following period, along with clearly manifested preference in the range of 30-110 cm (74\% of records), they were found along the entire length of the trays.

The first assumption is contradictory to the data on the young, the activity of which was higher not only compared to the adults in the gradient, but also compared to the control. Therefore, the extent of the activity of the Daphnia directly depended on the value of the tray length available for movement only over the initial, transitional period, after they were placed in the conditions of the temperature gradient.
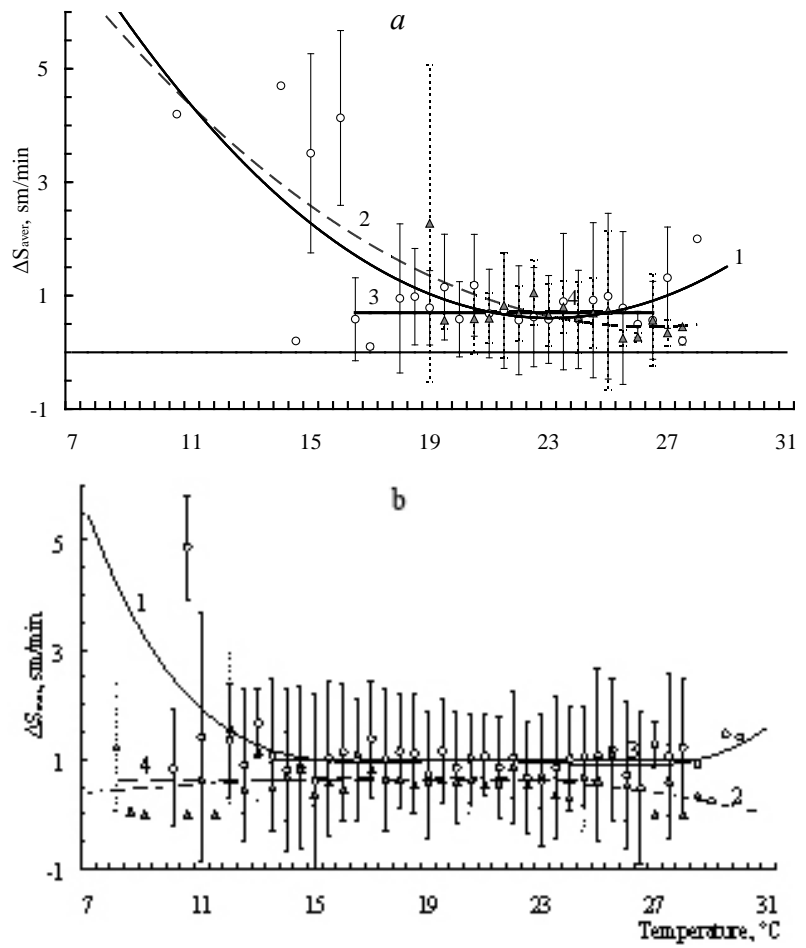

Fig. 6. Mean relative shifts $\left(\Delta \mathrm{S}_{\mathrm{aver}}\right)$ of a single $D$. magna individual depending on the temperature of the environment over the transitional period $(a)$ and over the period after reaching the level of FST $(b)$ :

1 - juveniles, 2 - parthenogenetic females, 3 - plateau zone

of the juveniles, 4 - plateau zone of adult females; each variant in 3 replications; vertical lines - standard deviations

It seems that the reason for the decreased activity of the adult Daphnia in the conditions of the temperature gradient was most likely a well known phenomenon, when in the preferred temperature range, many animals demonstrate minimum motor activity. Therefore, on the example of different species of crustaceans, it has been demonstrated that crustaceans acclimated to selected temperatures demonstrate lower motor activity (decrease in orthokinesis) (Fraenkel \& Gunn, 1961). Similar results were obtained for D. magna at $25{ }^{\circ} \mathrm{C}$ 
(Mckenzie, 1992), Homarus americanus at $20^{\circ} \mathrm{C}$ (McLeese \& Wilder, 1958) or between 15 and $19^{\circ} \mathrm{C}$ (Reynolds \& Casterlin, 1979a), and Astacus astacus at $15^{\circ} \mathrm{C}$ (Kivivuori, 1983).

This conclusion coincides with the data on the dynamics in the variability of the value of selected temperatures (ST) (Mazokhin-Porshnyakov \& Kartsev, 1979). During our experiment, the standard deviation of ST constantly increased among adult females $\left(1.7\right.$ to $\left.3.3^{\circ} \mathrm{C}\right)$, and young individuals $\left(2.0\right.$ to $\left.3.7^{\circ} \mathrm{C}\right)$, but the values of the young were constantly higher by $0.3-0.4{ }^{\circ} \mathrm{C}$ compared to the adults. Similar measurements made on the linear scale gave a similar result. The standard deviation of the selected position of the crustaceans on the linear scale increased among the adult females in the gradient from 26.0 to $43.5 \mathrm{~cm}$, from 32.0 to $53.5 \mathrm{~cm}$ among the young individuals, i. e. the values of variability of the young were higher by $6-10 \mathrm{~cm}$ compared to the adults. At the same time, the variability in the selection among the adult females in the control remained at the same high level of $46 \mathrm{~cm}$ throughout the experiment.

The high motor activity of the young individuals in the conditions of the temperature gradient could be caused by their presence in more heated water, which influenced both the increase in the total level of metabolism and motor activity. At the same time, a combination of high motor activity and selection of higher temperatures indicates the relationship between the behavioural selective reaction of juvenile Daphnia and the general physiological state of their organism, of which one of the parameters is motor activity. At the same time, the juveniles also proved the abovementioned assumption that motor activity decreases in the zone of selected temperatures. Having values of $\Delta \mathrm{S}_{\text {aver }}$ higher than the adults, the juvenile Daphnia demonstrated minimum values in the range of selected temperatures (Fig. 3), which was especially clear over the transitional period of 1-4 days.

The obtained data that the upper border of the juveniles' range of $\Delta \mathrm{S}_{\mathrm{aver}}$ values independent from temperature (plateau zone), which corresponds to the zone of the temperature optimum, was close to the one of the adults coincides with familiar assumption that the optimum temperatures are closer to the upper than to the lower critical temperatures. Reynolds \& Casterlin (1979) mentioned that the preferred temperature of warmwater fish is often within several degrees of the avoided or upper lethal temperatures. These authors think that the upper thermal borders are more accurately thermoregulated than the lower borders, and therefore, the distorted distribution indicates the preferred temperature. Such negatively distorted distribution of animals in relation to the preferred temperature was often observed in studies of temperature preference of many ectothermal species, including fish (DeWitt \& Fridman, 1979; Reynolds \& Casterlin, 1979b).

Asymmetry of motor reaction of Daphnia in the conditions of the thermogradient, which was manifested in predominance of shifts towards lower or higher temperatures, can indicate a clearly manifested search reaction in the conditions of non-uniform environment. For example, a similar result was obtained after ants were trained to search in a multi-alternative labyrinth (Udalova \& Karas, 1985, 1986). Similar behaviour was observed among Apis millifera honey bees and Paravespa vulgaris wasps (Mazokhin-Porshnyakov \& Kartsev, 1979), Oreochromis mossambicus Peters (Cichlidae) tilapia fish (Nepomnyashchikh \& Gremyachikh, 1993) and Gammarus crustaceans (G. oceanicus) (Udalova \& Karas, 1990) in the devices of "open field". It is considered that the asymmetry in the selection of direction is included in the search tactics and contributes to successful search behaviour (Miklosi et al., 2001; Nepomnyashchikh \& Izvekov, 2007; Andrew et al., 2009). However, if the asymmetry of reactions of lower invertebrates, insects and malacostracans can be explained by the functional asymmetry of the CNS and therefore asymmetry of left and right eyes, the mechanisms of asymmetry of motor reactions of Daphnia remain to be studied, especially in view of the peculiarity of their organ of sight - a single compound eye.

\section{Conclusions}

The earlier suggested assumption (Lagerspetz \& Vainio, 2006) that the decrease in the motor activity of ectotherms within the selec- ted temperature range is a behavioural mechanism typical for temperature selection was proved experimentally. Parthenogenetic Daphnia females kept for a long period in the conditions of a temperature gradient demonstrated motor activity $43.4 \%$ lower than when kept in water at constant temperature. The juveniles, whose total level of mean relative shifting was higher compared to the adults, had minimum values in the range of selected temperatures.
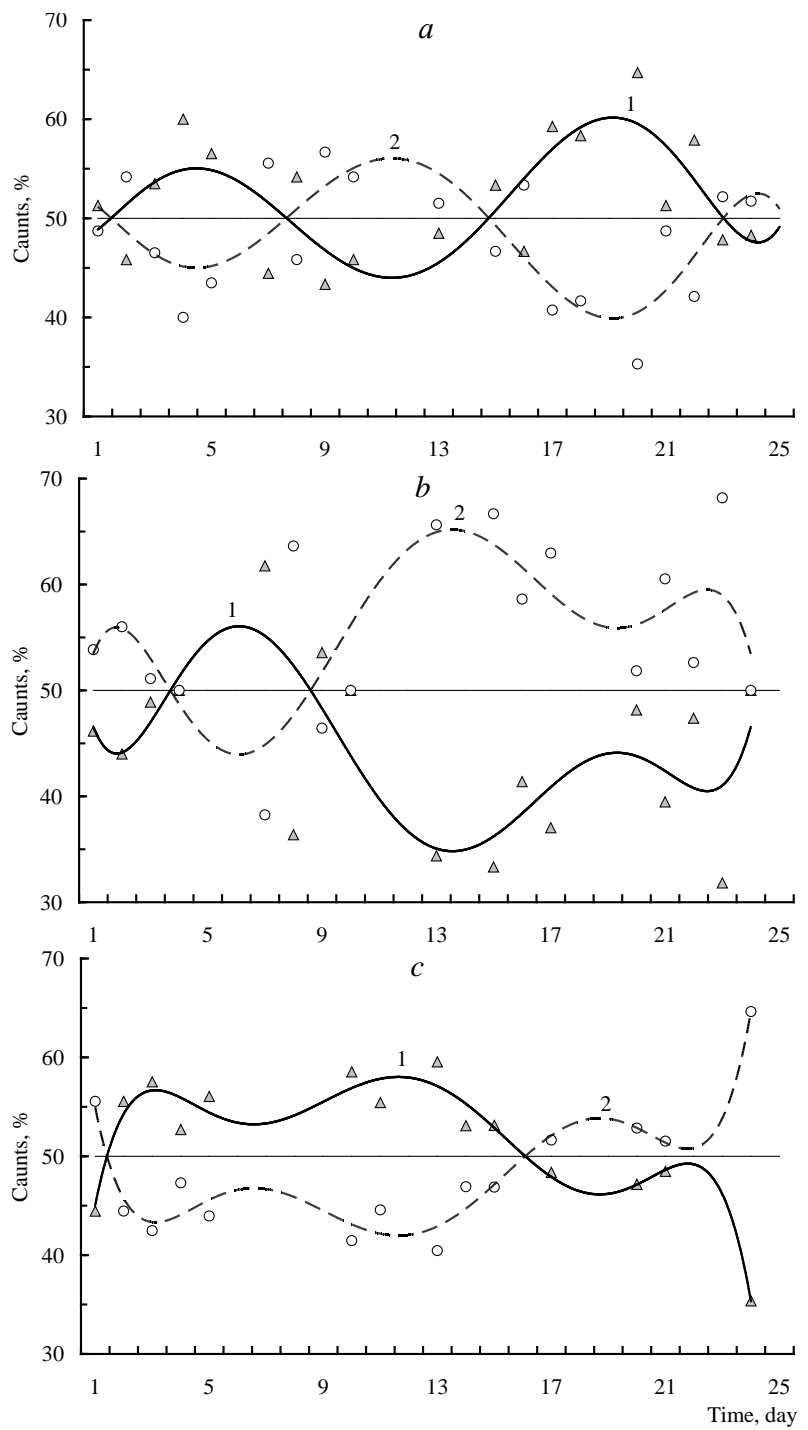

Fig. 7. Dynamic of the number of counts of relative shifts to the right (1) and to the left (2) (in \% of the total), a - adult females in the control, b - adult females in the gradient, $\mathrm{c}$ - juveniles in the gradient

The determined combination of higher motor activity of the juvenile Daphnia and reaction of selecting higher temperatures demonstrates the relationship between behavioural preference reaction and motor activity which characterizes the general condition of the organism. In the absence of the temperature gradient, the Daphnia showed symmetry of motor activity, which was manifested in the fluctuating cyclic pattern of sequence of predomination in the number of shifts to the right and to the left along the length of the tray. In the conditions of thermogradient, we observed asymmetry of motor activity, which was manifested among the adult females in the dominance of the number of shifts towards lower temperatures, and towards higher temperatures among the juveniles. Such behaviour indicates a clearer search reaction of the Daphnia in the conditions of a non-uniform environment.

The author expresses gratitude to V. D. Smirnov for technical servicing of the experimental setup and for his many-sided assistance in conducting the experiment. 


\section{References}

Andrew, R. J. (2009). Origins of asymmetry in the CNS. Seminars in Cell and Developmental Biology, 20, 485-490.

Andrew, R. J., Dharmaretnam, M., Györi, B., Miklosi, A., Watkins, J. A. S., \& Sovrano, V. A. (2009). Precise endogenous control of involvement of right and left visual structures in assessment by zebrafish. Behavioral Brain Research, 196, 99-105.

Bardach, J. E., \& Bjorklung, R. G. (1957). The temperature sensitivity of some American freshwater fishes. American Naturalist, 91, 233-251.

DeWitt, C. B., \& Fridman, R. M. (1979). Significance of skewness in ectotherm thermoregulation. American Zoology, 19, 195-209.

Espína, S., Díaz, F. H., \& Bückle, L. F. R. (1993). Preferred and avoided temperatures in the crawfish Procambarus clarkia (Decapoda, Cambaridae). Journal of Thermal Biology, 18, 35-39.

Fraenkel, G. S., \& Gunn, D. L. (1961). The orientation of animals. Kineses, taxes and compass reactions. Dover Publications Inc., New York.

Gautrais, J., Jost, C., Soria, M., Campo, A., Motsch, S., Fournier, R., Blanco, S \& Theraulaz, G. (2009). Analyzing fish movement as a persistent turning walker. Journal of Mathematical Biology, 58(3), 429-445.

Gerritsen, J. (1982). Behavioral response of Daphnia to rate of temperature change: Possible enhancement of vertical migration. Limnology and Oceanography, 27, 254-261.

Golovanov, V. K. (2013). Temperaturnyye kriterii zhiznedeyatel'nosti presnovodnykh ryb [Temperature criteria for vital activity of freshwater fish]. Polygraph-Plus, Moscow (in Russian).

Gorska-Andrzejak, J., \& Wojtusiak, J. (2003). A comparative study of the leve of locomotor activity throughout postembryonic development of two cricket species: Acheta domesticus L. and Gryllus bimaculatus De Geer (Ensifera: Gryllidae). Journal of Insect Behavioral, 16(6), 845-857.

Jury, S. H., \& Watson, W. H. III. (2000). Thermosensitivity of the lobster, Homarus americanus, as determined by cardiac assay. Biological Bulletin, 199, 257-264.

Izvekov, E. I., \& Nepomnyashchikh, V. A. (2013) Asymmetry of the behavioral response in roach Rutilus rutilus (L.) (Teleostei: Cyprinidae) to a new object. Inland Water Biology, 6(4), 68-73.

Kivivuori, L. A. (1983). Temperature acclimation of walking in the crayfish Astacus astacus L. Comparative Biochemistry and Physiology, 75A, 375-378.

Kivivuori, L. A. (1994). Temperature selection behaviour of cold and warm-acclimated crayfish (Astacus astacus (L.). Journal of Thermal Biology, 19, 291-297.

Lagerspetz, K. Y. H., \& Vainio L. A. (2006). Thermal behaviour of crustaceans. Biological Review, 1, 1-22.

Mazokhin-Porshnyakov, G. A., \& Kartsev, V. M. (1979). Izucheniye posledovatel'nosti obleta nasekomymi neskol'kikh ravnotsennykh pishchevykh ob’yektov (k voprosu o strategii ikh vizual'nogo poiska) [Study of the sequence of flying by insects to several equivalent food objects (to the question of the strategy of their visual search)]. Zoological Journal, 58(9), 1281-1289 (in Russian).

Mckenzie, J. D., Clow, P., Clyde, J., Miles, A., Dickinson, R., Lieb, W. R., \& Franks, N. P. (1992). Effects of temperature on the anaesthetic potency of halothane, enflurane and ethanol in Daphnia magna (Cladocera: Crustacea). Comparative Biochemistry and Physiology. Part C. Comparative Pharmacology and Toxicology, 101, 15-19.

McLeese, D. W., \& Wilder, D. G. (1958). The activity and catchability of the lobster (Homarus americanus) in relation to temperature. Journal of the Fisheries Research Board of Canada, 15(6), 1345-1354.

Miklosi, A., Andrew, R. J., \& Gasparini, S. (2001). Role of right hemifield in visual control of approach to target in zebra fish. Behavioural Brain Research, 122, 57-65.

Miklosi, A., \& Andrew, R. J. (1999). Right eye use associated with decision to bite in zebrafish. Behavioural Brain Research, 105, 199-205.
Miklosi, A., Andrew, R. J., \& Savage, H. (1997). Behavioural lateralisation of the tetrapod type in the zebrafish (Brachydanio rerio). Physiology and Behavior, 63, 127-135.

Nepomnyashchikh, V. A. (2000). Izmenchivost' reaktsii na zritel'nyy razdrazhitel' u zolotykh rybok Carassius auratus L. (Cyprinidae: Pisces) [The variability of the reaction to the visual stimulus in goldfish Carassius auratus L. (Cyprinidae: Pisces)]. Journal of General Biology, 61(2), 315-324 (in Russian).

Nepomnyashchikh, V. A., \& Gremyachikh, V. A. (1993). Svyaz' mezhdu strukturoy trayektorii i asimmetriyey vybora napravleniya dvizheniya u tilyapii Oreochromis mossambicus Peters (Cichlidae) [The relationship between the structure of the trajectory and the asymmetry of the direction of motion in tilapia Oreochromis mossambicus Peters (Cichlidae)]. Journal of General Biology, 54(5), 619-626 (in Russian).

Nepomnyashchikh, V. A., \& Izvekov, E. I. (2007). Laterality of behavioral responses in bony fishes: Inheritance, adaptive importance, and morphofunctional correlates. Journal of Ichthyology, 47(9), 782-790.

Reynolds, W. W., \& Casterlin, M. E. (1979a). Behavioral thermoregulation and activity in Homarus americanus. Comparative Biochemistry and Physiology. 65A, 25-28.

Reynolds, W. W., \& Casterlin, M. E. (1979b). Behavioral thermoregulation and the "final preferendum" paradigm. American Zoologist, 19, 211-224.

Romanovsky, A. V., Pesnya, D. S., Izvekov, E. I., Krylov, V. V., \& Nepomnyashchy, V. A. (2014). Povedeniye samtsov Danio rerio Hamilton posle vozdeystviya imitatsii magnitnoy buri na ikh embriony [Behavior of the male Danio rerio Hamilton after the impact of imitation of a magnetic storm on their embryos]. Biophysics, 59(6), 1151-1156 (in Russian).

Rosetti, Y., Rosetti, L., \& Cabanac, M. (1989). Annual oscillation of preferred temperature in the freshwater snail Lymnaea awicularia: Effect of light and temperature. Animal Behaviour, 37(6), 897-907.

Steffel, S., Dizon, A. E., Magnuson, J. J., \& Neill, W. H. (1976). Temperature discrimination by captive tree-swimming tuna, Euthynnus affinis. Transactions of the American Fisheries Society, 105(5), 588-591.

Takeuchi, Y., Hori, M., Myint, O., \& Kohda, M. (2010). Lateral bias of agonistic responses to mirror images and morphological asymmetry in the Siamese fighting fish (Betta splendens). Behavioural Brain Research, 208(1), 106-111.

Udalova, G. P., \& Karas, A. Y. (1985). Asimmetriya napravleniya dvizheniya u murav'yev Myrmica rubra pri obuchenii v labirinte [Asymmetry of the direction of motion of the Myrmica rubra ants when training in a labyrinth]. Journal of Higher Nervous Activity I. P. Pavlova, 35(2), 377-379 (in Russian).

Udalova, G. P., \& Karas, A. Y. (1986). Asimmetriya napravleniya dvizheniya u murav'yev Myrmica rubra pri obuchenii v labirinte $\mathrm{v}$ usloviyakh pishchevoy motivatsii [Asymmetry of the direction of movement of Myrmica rubra ants when training in a labyrinth in conditions of food motivation]. Journal of Higher Nervous Activity I. P. Pavlova, 36(4), 707 714 (in Russian).

Udalova, G. P, Karas, A. Y., \& Zhukovskaya, M. I. (1990). Asimmetriya napravleniya dvizheniya u gammarusov (Gammarus oceanicus) v teste otkrytogo polya [Asymmetry of the direction of movement in gammarus (Gammarus oceanicus) in the open field test]. Journal of Higher Nervous Activity I. P. Pavlova, 40(1), 93-101 (in Russian).

Vallortigara, G., \& Bisazza, A. (2002). How ancient is brain lateralization? Comparative vertebrate lateralization. The evolution of brain lateralization. Cambridge University Press, Cambridge. Pp. 9-69.

Verbitskii, V. B., \& Verbitskaya, T. I. (2012). Thermal preference and avoidance in cladoceran Daphnia magna Strauss (Crustacea, Cladocera) acclimated to constant temperature. Biological Bulletin, 39(1), 93-98.

Wang, G., \& Greenfield, M. D. (1994). Ontogeny of territoriality in the desert clicker Ligurotettix coquilletti (Orthoptera: Acrididae). Journal of Insect Behavior, 7, 327-342. 